\title{
Behaviour Analysis of Availability of Feeding System in the Sugar Industry
}

\author{
Dr. Zeenat Zaidi \\ Assistant Professor, Statistics, Deanship of Educational Services, Qassim University, Saudi Arabia
}

\begin{abstract}
This paper explains a methodology to study the transient and steady state behaviour of the feeding system in the sugar industry. The mathematical formulation of the system is done with the help of Markov method using mnemonic rule. The failure and repair rates of the subsystem are taken as constant. Availability in the transient state is evaluated with the help of matrix method using $C$ - program. Numerical results are presented with the help of MATLAB (7.8.0.347 R2009a) to illustrate the steady state behaviour of the system. The bottlenecks of the system are identified through availability analysis of feeding system which could help in improving its availability. And this can be considered to be useful for determining the best possible maintenance strategies.
\end{abstract}

Keywords: Availability, Bottleneck, Matrix method, Maintenance strategies, Transient state and steady state

\section{Introduction and Background}

The key objective of process industries is to increase the productivity and to cut down the production cost. The goal can be achieved by increasing reliability/availability of the system. In order to increase the reliability/availability of a system, redundancy in subsystems is introduced. By adding redundant components, the system availability can be increased to a reasonable level but complexity in the system increased. Such systems are divided into parts for finding the availability. The Sugar industry is a complex continuous process. The system is divided into three main parts for analysis, namely, feeding, refining and crystallization. In the present paper, the feeding system of sugar industry has been analyzed and studied. Failure and repair rates of each subsystem are assumed to be constant. The Mathematical model has been developed using Markov birth - death process. The differential equations thus formed are solved with the help of Matrix method using C- Program. The equations are further solved using recursive method and normalizing condition so as to estimate steady state availability of the system.

The concept of availability is widely discussed in literature and the main contributors are Barlow and Hunter [1960], Gaver [1963], Sandler [1963], Myers [1964], Barlow and Proschan [1965], Rau [1970]. Singh and Billington [1974, 1975] suggest methods for determining the frequency of failures of complex systems. In the last 35 years, various research papers and books have been published related to reliability technology. Dhillon et al. [1] have frequently used the Markovian approach for the availability analysis, using exponential distribution for failure and repair times. Kumar et al. [2, 3, 4, and 6] dealt with reliability, availability and operational behaviour analysis for different systems in the paper plant. Dayal and Singh [5] studied reliability analysis of a system in a fluctuating environment. Zhao [7] developed a generalized availability model for repairable component and series system including perfect and imperfect repair. Shooman [8] discussed the reliability computation for systems with dependent failures. Michelson [9] explained the use of reliability technology in process industry. Singh and Mahajan [10] examined the reliability and long run availability of a Utensils manufacturing Plant using Laplace
Transforms. Gunes and Deveci [11] have studied the reliability of service systems and its application in student office. And Habchi [12] discussed an improved method of reliability assessment for suspended tests. Castro and Cavalca [13] presented an availability optimization problem of an engineering system assembled in series configuration which has redundancy of units and teams of maintenance as optimization parameters. Tewari, Joshi and Rao [14] discussed about the mathematical modeling and behavioural analysis of a refining system using genetic algorithm. Gupta, Lal, Sharma and Singh [15] discussed the reliability, long term availability and MTBF of cement industry with the help of Runge-Kutta method. Singh and Goyal [16] discussed availability in Bread manufacturing plant. Kiureghian and Ditlevson [17] analysed the availability, reliability and downtime of system with repairable components. Kumar, Singh and Sharma discussed the availability of an automobile system namely -scooty". Jussi K. Vaurio [18] discussed current research and application related to the modeling, optimization and application of maintenance procedures for ageing and deteriorating engineering and structural systems. In the above papers, authors used either Laplace transforms method or Lagrange's method or Runge kutta method to solve differential equations which involves complex calculations. Hence it has been observed that calculation of availability in transient state is very difficult in complex systems. In fact, problem of calculating variation of availability with time has not satisfactorily been tackled till now. In this paper, we have developed the matrix method to solve differential equations in transient state. The Matrix Method provides an easy way to estimate the variation in system performance in terms of availability with respect to time and computer program is developed to calculate the time dependent availability. The time dependent availability of the feeding system is also shown with the help of graph. Long run availability is also studied with the help of tables at different repair rates. The tables for the estimation of time dependent availability are prepared by $\mathrm{C}$ - Programming and tables for steady state availability are formed with the help of MATLAB 7.8.0 (R2009a). The results are useful for the chemical and reliability engineers. The findings of the analysis depict which subsystems and equipment are critical from availability standpoint. Hence, weak spots of the industry could be identified and maintained. 


\section{International Journal of Science and Research (IJSR) \\ ISSN (Online): 2319-7064}

Index Copernicus Value (2013): 6.14 | Impact Factor (2014): 5.611

This paper is organized in six sections. The present section is introductory in nature. In section 2, a brief description of the Sugar industry is presented and also subsystems of feeding system are explained. In section 3, notations and certain assumptions on which present analysis is based are also given. In Section 4, availability in transient state has been calculated and time dependent availability graph is prepared. And also tables are formulated showing the effect of failure and repair rates on the availability of the system. In Section 5 , steady state analysis has been done and tables are developed using MATLAB software. And section 6 gives the analysis of above results.

\section{System Description}

The Sugar industry is divided into three main parts, namely, feeding, refining and crystallization. The feeding system is analysed here for its availability.

In a Sugar plant, the raw material (sugarcane) is fed to cutters by a chain conveyor system for chopping. The chopped pieces are sent to crushers to squeeze the sugarcane for maximum possible extraction of juice. The juice so obtained contains impurities like small pieces of bagasse, mud, etc. And hence it is passed through a number of filters in series for refining. The juice is heated up by steam to attain a definite temperature and $\mathrm{PH}$ value. Then Sulphur dioxide gas is passed and the juice is next sent through a clarifier where further separation of mud by gravity takes place. The clear juice so obtained is stored in a evaporator where the juice water evaporates and passes through sulphitor for final refining. The concentrated and refined juice is taken to cooking pans where the remaining juice water gets evaporated, converting the juice to viscous fluid. Then this is transferred for crystallization process.

The Feeding System of the Sugar Industry consists of four subsystems, out of which subsystem C and D are working in reduced capacities.

1) Sugarcane supply system (A)

This system comprises three units in series-chain conveyor to carry the sugarcane to cutters, cutter for chopping the sugarcane into small pieces and chain conveyor for carrying small pieces to crushing units. The failure of anyone unit causes the major failure.

2) The Crushing system (B):

This system consists of five or six units in series. Failure of any one unit causes failure of the system.

3) The Bagasse carrying unit (C):

This system consists of two or three units. Failure of any one unit leads to the reduction in efficiency of the system.

4) The Heat generation system (D):

It consists of three boilers in parallel. The failure of a boiler means the reduction in the efficiency of the system.

\section{Assumptions and Notations}

The assumptions used in developing the mathematical model are as follows:

- Failure rates and repair rates are constant over time and statistically independent.

- A repaired unit as good as new, performance wise, for a specified duration.
- Sufficient repair facilities are provided.

- Standby units are of the same nature as that of active units.

- Service includes repair and / or replacement.

- System may work at reduced capacity.

A, B, C, D: Subsystems in good operating state.

a, b, c, d: Indicates the failed state of A, B, C and D.

$\overline{\mathrm{C}}, \overline{\mathrm{D}}$ : Indicates that the subsystems $\mathrm{C}$ and $\mathrm{D}$ are working at reduced capacity.

$\alpha_{\mathrm{i}}(i=1,2,3,4,5,6)$ : Represents failure rates of the subsystems A, B, C, $\overline{\mathrm{C}}, \mathrm{D}, \overline{\mathrm{D}}$.

$\beta_{i}(i=1,2,3,4,5,6)$ : Represents repair rates of the subsystems a, b, $\overline{\mathrm{C}}, \mathrm{c}, \overline{\mathrm{D}}$ and $\mathrm{d}$.

$\mathrm{P}_{\mathrm{i}}(\mathrm{t})$ : Probability that at time $\mathrm{t}^{\mathrm{t}}$, the system is in $\mathrm{i}^{\text {th }}$ state.

Based on these assumptions and notations, transition diagram is drawn and differential equations are developed using mnemonic rule.

\section{Transient state Availability of the system}

For finding out the time dependent availability of the system, the system of linear differential equations are developed by means of mnemonic rule and solved by matrix method using C- program. The differential equations $(1-5)$ can be written as,

$$
\begin{aligned}
& \mathrm{P}_{0}^{\prime}(\mathrm{t})+\left(\alpha_{1}+\alpha_{2}+\alpha_{3}+\alpha_{5}\right) \mathrm{P}_{0}(\mathrm{t})=\beta_{1} \mathrm{P}_{4}(\mathrm{t})+\beta_{2} \mathrm{P}_{5}(\mathrm{t})+\beta_{3} \mathrm{P}_{1}(\mathrm{t})+\beta_{5} \mathrm{P}_{2}(\mathrm{t}) \\
& \ldots \ldots \ldots . .1 \\
& \mathrm{P}_{1}^{\prime}(\mathrm{t})+\left(\alpha_{1}+\alpha_{2}+\alpha_{4}+\alpha_{5}+\beta_{3}\right) \mathrm{P}_{1}(\mathrm{t})=\beta_{1} \mathrm{P}_{6}(\mathrm{t})+\beta_{2} \mathrm{P}_{7}(\mathrm{t})+\beta_{4} \mathrm{P}_{8}(\mathrm{t}) \\
& +\beta_{5} \mathrm{P}_{3}(\mathrm{t})+\alpha_{3} \mathrm{P}_{0}(\mathrm{t}) \\
& \ldots \ldots \ldots \ldots 2
\end{aligned}
$$

$$
\begin{aligned}
& \mathrm{P}_{2}^{\prime}(\mathrm{t})+\left(\alpha_{1}+\alpha_{2}+\alpha_{3}+\alpha_{6}+\beta_{5}\right) \mathrm{P}_{2}(\mathrm{t})=\beta_{1} \mathrm{P}_{9}(\mathrm{t})+\beta_{2} \mathrm{P}_{10}(\mathrm{t})+\beta_{3} \mathrm{P}_{3}(\mathrm{t}) \\
& +\beta_{6} \mathrm{P}_{11}(\mathrm{t})+\alpha_{5} \mathrm{P}_{0}(\mathrm{t}) \\
& \ldots \ldots .3 \\
& \mathrm{P}_{3}^{\prime}(\mathrm{t})+\left(\alpha_{1}+\alpha_{2}+\alpha_{4}+\alpha_{6}+\beta_{3}+\beta_{5}\right) \mathrm{P}_{3}(\mathrm{t})=\beta_{1} \mathrm{P}_{12}(\mathrm{t})+\beta_{2} \mathrm{P}_{13}(\mathrm{t}) \\
& +\beta_{4} \mathrm{P}_{14}(\mathrm{t})+\beta_{6} \mathrm{P}_{15}(\mathrm{t})+\alpha_{3} \mathrm{P}_{2}(\mathrm{t})+\alpha_{5} \mathrm{P}_{1}(\mathrm{t}) \\
& \ldots \ldots . .4 \\
& \mathrm{P}_{j}^{\prime}(\mathrm{t})+\beta_{i} \mathrm{P}_{\mathrm{j}}(\mathrm{t})=\alpha_{\mathrm{i}} \mathrm{P}_{\mathrm{k}}(\mathrm{t}) \ldots \ldots . .5
\end{aligned}
$$

where, (for $\mathrm{i}=1,2: \mathrm{j}=4,5$ when $\mathrm{k}=0$ ), (for $\mathrm{i}=1,2,4, \mathrm{j}=6$, $7,8$ when $\mathrm{k}=1)$, (for $\mathrm{i}=1,2,6: \mathrm{j}=9,10,11$ when $\mathrm{k}=2$ ), (for $\mathrm{i}=1,2,4,6: \mathrm{j}=12,13,14,15$ when $\mathrm{k}=3$ )

With initial conditions at time $\mathrm{t}=0$

$$
\begin{aligned}
\mathrm{P}_{\mathrm{i}}(\mathrm{t}) & =1 \text { for } \mathrm{i}=0 \\
& =0 \text { for } \mathrm{i} \neq 0
\end{aligned}
$$

The equations from (1) to (5) are solved by using matrix method using $\mathrm{C}-$ Program. The availability of the system is given by $\operatorname{Av}(\mathrm{t})=\mathrm{P}_{0}(\mathrm{t})+\mathrm{P}_{1}(\mathrm{t})+\mathrm{P}_{2}(\mathrm{t})+\mathrm{P}_{3}(\mathrm{t})$

The availability of the system is obtained by solving the matrix differential difference equations 


\section{International Journal of Science and Research (IJSR) \\ ISSN (Online): 2319-7064 \\ Index Copernicus Value (2013): 6.14 | Impact Factor (2014): 5.611}

$(\theta \mathrm{I}-\mathrm{A}) \overline{\mathrm{P}}_{\mathrm{i}}(\mathrm{t})=\mathrm{O}$, where $\theta \equiv \mathrm{d} / \mathrm{dt}$, $\mathrm{O}$ is the null matrix, matrix $A$ is the matrix of the coefficients of the probability states $p_{i}(t)$ and $I$ or $I_{n}$ is the identity matrix of order $n$.

The equations reduce to $C^{-1}(\theta I-D) \bar{P}_{i}(t)=O$, where $C$ is the matrix such that $C^{-1} A C=D$, and $D=\left(d_{1}, d_{2}, \ldots ., d_{n}\right)$ is the matrix of Eigen values of the matrix $\mathrm{A}$.

The availability of the system is sum of the availabilities of working subsystems.

$\operatorname{Av}(\mathrm{t})=\mathrm{P}_{0}(\mathrm{t})+\mathrm{P}_{1}(\mathrm{t})+\mathrm{P}_{2}(\mathrm{t})+\mathrm{P}_{3}(\mathrm{t})$

$=1+\left(a_{11}+a_{21}+a_{31}+a_{41}\right) t+\left(b_{11}+b_{21}+b_{31}+b_{41}\right) t^{2} / 2$ !

$+\ldots \ldots$.

The entries $\mathrm{a}_{\mathrm{ij}}, \mathrm{b}_{\mathrm{ij}}$ etc. are respective entries in $\mathrm{A}, \mathrm{B}=\mathrm{A} \overline{\mathrm{P}}_{\mathrm{i}}(0)$, $\mathrm{C}=\mathrm{AB}=\mathrm{A}^{2} \overline{\mathrm{P}}_{\mathrm{i}}(0)$ so on.

The Matrix $\mathrm{A}=$

$\left[\begin{array}{cccccccccccccccc}-A_{1} & \beta_{3} & \beta_{5} & 0 & \beta_{1} & \beta_{2} & 0 & 0 & 0 & 0 & 0 & 0 & 0 & 0 & 0 & 0 \\ \alpha_{3} & -A_{2} & 0 & \beta_{5} & 0 & 0 & \beta_{1} & \beta_{2} & \beta_{4} & 0 & 0 & 0 & 0 & 0 & 0 & 0 \\ \alpha_{5} & 0 & -A_{3} & \beta_{3} & 0 & 0 & 0 & 0 & 0 & \beta_{1} & \beta_{2} & \beta_{6} & 0 & 0 & 0 & 0 \\ 0 & \alpha_{5} & \alpha_{3} & -A_{4} & 0 & 0 & 0 & 0 & 0 & 0 & 0 & 0 & \beta_{1} & \beta_{2} & \beta_{4} & \beta_{6} \\ \alpha_{1} & 0 & 0 & 0 & -\beta_{1} & 0 & 0 & 0 & 0 & 0 & 0 & 0 & 0 & 0 & 0 & 0 \\ \alpha_{2} & 0 & 0 & 0 & 0 & -\beta_{2} & 0 & 0 & 0 & 0 & 0 & 0 & 0 & 0 & 0 & 0 \\ 0 & \alpha_{1} & 0 & 0 & 0 & 0 & -\beta_{1} & 0 & 0 & 0 & 0 & 0 & 0 & 0 & 0 & 0 \\ 0 & \alpha_{2} & 0 & 0 & 0 & 0 & 0 & -\beta_{2} & 0 & 0 & 0 & 0 & 0 & 0 & 0 & 0 \\ 0 & \alpha_{4} & 0 & 0 & 0 & 0 & 0 & 0 & -\beta_{4} & 0 & 0 & 0 & 0 & 0 & 0 & 0 \\ 0 & 0 & \alpha_{1} & 0 & 0 & 0 & 0 & 0 & 0 & -\beta_{1} & 0 & 0 & 0 & 0 & 0 & 0 \\ 0 & 0 & \alpha_{2} & 0 & 0 & 0 & 0 & 0 & 0 & 0 & -\beta_{2} & 0 & 0 & 0 & 0 & 0 \\ 0 & 0 & \alpha_{6} & 0 & 0 & 0 & 0 & 0 & 0 & 0 & 0 & -\beta_{6} & 0 & 0 & 0 & 0 \\ 0 & 0 & 0 & \alpha_{1} & 0 & 0 & 0 & 0 & 0 & 0 & 0 & 0 & -\beta_{1} & 0 & 0 & 0 \\ 0 & 0 & 0 & \alpha_{2} & 0 & 0 & 0 & 0 & 0 & 0 & 0 & 0 & 0 & -\beta_{2} & 0 & 0 \\ 0 & 0 & 0 & \alpha_{4} & 0 & 0 & 0 & 0 & 0 & 0 & 0 & 0 & 0 & 0 & -\beta_{4} & 0 \\ 0 & 0 & 0 & \alpha_{6} & 0 & 0 & 0 & 0 & 0 & 0 & 0 & 0 & 0 & 0 & 0 & -\beta_{6}\end{array}\right]$

The availability of the system is calculated for different values of the failure and repair rates. And Table-1, Fig. 2 is developed with the help of Matrix method using C Program. The value of failure and repair rate are taken constant

$$
\begin{aligned}
&\left(\alpha_{1}=0.001\right),\left(\alpha_{2}=0.002\right),\left(\alpha_{3}=0.001\right),\left(\alpha_{4}=0.002\right), \text { as: }\left(\alpha_{5}=0.001\right),\left(\alpha_{6}=0.001\right),\left(\beta_{1}=0.025\right),\left(\beta_{2}=0.01\right), \\
&\left(\beta_{3}=0.02\right),\left(\beta_{4}=0.025\right),\left(\beta_{5}=0.01\right),\left(\beta_{6}=0.015\right) .
\end{aligned}
$$

Table 1

\begin{tabular}{|c|c|c|c|c|c|}
\hline Time & $\mathbf{1 0}$ & $\mathbf{2 0}$ & $\mathbf{3 0}$ & $\mathbf{4 0}$ & $\mathbf{5 0}$ \\
\hline Availability & 0.972396 & 0.949026 & 0.929168 & 0.912235 & 0.897745 \\
\hline Time & $\mathbf{6 0}$ & $\mathbf{7 0}$ & $\mathbf{8 0}$ & $\mathbf{9 0}$ & $\mathbf{1 0 0}$ \\
\hline Availability & 0.885314 & 0.874654 & 0.865621 & 0.858330 & 0.853417 \\
\hline
\end{tabular}

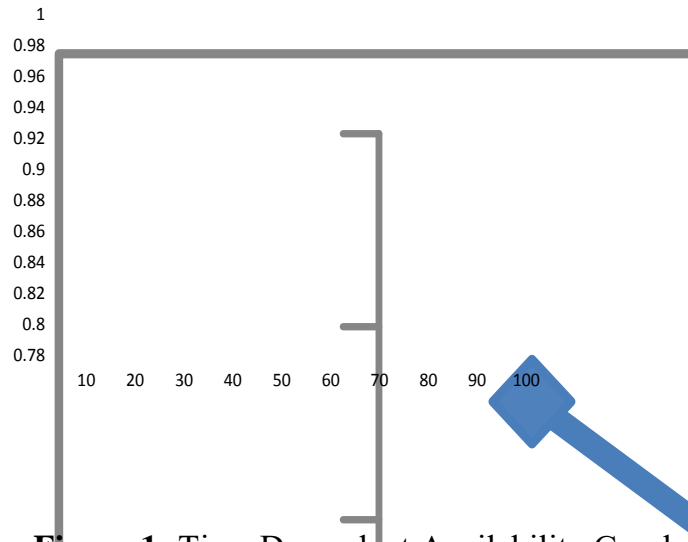

Figure 1: Time Dependent Availability Graph

Program used:

\#include $<$ stdio.h $>$

//\#include < conio.h $>$

int main()

\{

float b[16][16],c[16][16],d[16][16],e[16][16],f[16][16];

float

$\mathrm{g}[16][16], \mathrm{h}[16][16], \mathrm{o}[16][16], \mathrm{p}[16][16], \mathrm{q}[16][16], \mathrm{r}[16][16]$;

float $\mathrm{x} 1, \mathrm{x} 2, \mathrm{x} 3, \mathrm{x} 4, \mathrm{x} 5, \mathrm{x} 6, \mathrm{x} 7, \mathrm{x} 8, \mathrm{x} 9, \mathrm{x} 10, \mathrm{x} 11, \mathrm{x}$;

int $\mathrm{i}, \mathrm{j}, \mathrm{l}=12, \mathrm{n}=12, \mathrm{~m}=12, \mathrm{t}=10$;

float $\mathrm{a}[16][16]=\{-.005, .02, .01,0, .025, .01,0,0,0,0,0,0,0,0,0,0$,

$.001,-.026,0, .01,0,0, .025, .01, .025,0,0,0,0,0,0,0$,

$.001,0,-.015, .02,0,0,0,0,0, .025, .01, .015,0,0,0,0$,

$0, .001, .001,-.036,0,0,0,0,0,0,0,0, .025, .01, .025, .015$

$.001,0,0,0,-.025,0,0,0,0,0,0,0,0,0,0,0$,

$.002,0,0,0,0,-.01,0,0,0,0,0,0,0,0,0,0$,

$0, .001,0,0,0,0,-.025,0,0,0,0,0,0,0,0,0$,

$0, .002,0,0,0,0,0,-.01,0,0,0,0,0,0,0,0$,

$0, .002,0,0,0,0,0,0,-.025,0,0,0,0,0,0,0$,

$0,0, .001,0,0,0,0,0,0,-.025,0,0,0,0,0,0$,

$0,0, .002,0,0,0,0,0,0,0,-.01,0,0,0,0,0$,

$0,0, .001,0,0,0,0,0,0,0,0,-.015,0,0,0,0$,

$0,0,0, .001,0,0,0,0,0,0,0,0,-.025,0,0,0$,

$0,0,0, .002,0,0,0,0,0,0,0,0,0,-.01,0,0$,

$0,0,0, .002,0,0,0,0,0,0,0,0,0,0,-.025,0$,

$0,0,0, .001,0,0,0,0,0,0,0,0,0,0,0,-.015\}$

// $\operatorname{clrscr}()$;

for $(\mathrm{i}=0 ; \mathrm{i}<\mathrm{m} ; \mathrm{i}++)$

for $(j=0 ; j<n ; j++)$

$\mathrm{b}[\mathrm{i}][\mathrm{j}]=\mathrm{a}[\mathrm{i}][\mathrm{j}]$;

\}

for $(\mathrm{i}=0 ; \mathrm{i}<\mathrm{m} ; \mathrm{i}++)$

\{

for $(j=0 ; j<n ; j++)$

\{

$\mathrm{c}[\mathrm{i}][\mathrm{j}]=0$;

for $(\mathrm{l}=0 ; 1<\mathrm{m} ; \mathrm{l}++)$

$c[i][j]=(((a[i][j] * b[1][j]) * t) / 2)+c[i][j]$;

\}

\} 


\section{International Journal of Science and Research (IJSR) \\ ISSN (Online): 2319-7064 \\ Index Copernicus Value (2013): 6.14 | Impact Factor (2014): 5.611}

///The process of multiplication of matrices goes on depending upon the acceptance of the computer, to get more accuracy.

$\mathrm{x} 1=((\mathrm{a}[0][0]+\mathrm{a}[1][0]+\mathrm{a}[2][0]+\mathrm{a}[3][0]) * \mathrm{t}) ;$

$\mathrm{x} 2=((\mathrm{b}[0][0]+\mathrm{b}[1][0]+\mathrm{b}[2][0]+\mathrm{b}[3][0]) * \mathrm{t})$;

$\mathrm{x} 3=((\mathrm{c}[0][0]+\mathrm{c}[1][0]+\mathrm{c}[2][0]+\mathrm{c}[3][0]) * \mathrm{t})$;

As many times we multiply, the matrices we take notations $\mathrm{x} 1, \mathrm{x} 2$ etc.

printf("\n \n

$\mathrm{f}(\mathrm{t})=1+\% \mathrm{f}+\% \mathrm{f}+\% \mathrm{f}+\% \mathrm{f}+\% \mathrm{f}+\% \mathrm{f}+\% \mathrm{f}+\% \mathrm{f}+\% \mathrm{f}+\% \mathrm{f}+\% \mathrm{f}+\% \mathrm{f}$, $\mathrm{x}$

$1, \mathrm{x} 2, \mathrm{x} 3, \mathrm{x} 4, \mathrm{x} 5, \mathrm{x} 6, \mathrm{x} 7, \mathrm{x} 8, \mathrm{x} 9, \mathrm{x} 10, \mathrm{x} 11, \mathrm{x} 12)$

$\mathrm{x}=1+\mathrm{x} 1+\mathrm{x} 2+\mathrm{x} 3+\mathrm{x} 4+\mathrm{x} 5+\mathrm{x} 6+\mathrm{x} 7+\mathrm{x} 8+\mathrm{x} 9+\mathrm{x} 10+\mathrm{x} 11+\mathrm{x} 12$

printf("\n\n $\left.\mathrm{x}=\% \mathrm{f}^{\mathrm{f}}, \mathrm{x}\right)$;

$\operatorname{getch}()$;

\}

\subsection{Numerical Illustrations in Transient State}

The effect of parameters on the availability of the system is tabulated with the help of above program and shown in tables ' no. 2 to 7 in the time horizon of 10 months to 50 months. It has been observed from the tabular values that failure rate increases, the availability of the system decreases as seen from the table no. 2 to 5 . And by increasing the repair rate, the availability of the system increases significantly as observed from table no. 6 and 7.

a) Effect of failure rate of Sugarcane supply system $\left(\alpha_{1}\right)$ on the availability of the system. (Table - 2)

\begin{tabular}{|c|c|c|c|c|}
\hline Months $/ \alpha_{1}$ & 0.001 & 0.003 & 0.005 & 0.007 \\
\hline 10 & 0.972396 & 0.955384 & 0.938695 & 0.922322 \\
\hline 20 & 0.949026 & 0.919897 & 0.891814 & 0.864737 \\
\hline 30 & 0.929168 & 0.891511 & 0.855769 & 0.821837 \\
\hline 40 & 0.912235 & 0.868668 & 0.827885 & 0.789691 \\
\hline 50 & 0.897745 & 0.850172 & 0.806177 & 0.765459 \\
\hline
\end{tabular}

Table No. 2 shows the effect of failure rate of system A on the availability of the system. The availability of the system decreases significantly by $21.28 \%$ by varying the failure rate from 0.001 to 0.007 in a step size of 0.002 .

b) Effect of failure rate of Crushing system ( $\left.\alpha_{2}\right)$ on the availability of the system. (Table - 3 )

\begin{tabular}{|l|l|l|l|l|}
\hline Months $/ \alpha_{2}$ & 0.002 & 0.004 & 0.006 & 0.008 \\
\hline 10 & 0.972396 & 0.954091 & 0.936142 & 0.918543 \\
\hline 20 & 0.949026 & 0.915422 & 0.883090 & 0.851982 \\
\hline 30 & 0.929168 & 0.882772 & 0.838936 & 0.797513 \\
\hline 40 & 0.912235 & 0.855137 & 0.802117 & 0.752872 \\
\hline 50 & 0.897745 & 0.831694 & 0.771364 & 0.716236 \\
\hline
\end{tabular}

Table No. 3 shows the effect of failure rate of Subsystem B on the availability of the system. The availability of the system decreases by $26.34 \%$ by varying the failure rate from 0.002 to 0.008 in a stepsize of 0.002 . c) Effect of failure rate of Bagasse carrying unit from reduced state to failed state $\left(\alpha_{4}\right)$ on the availability of the system (Table - 4)

\begin{tabular}{|c|c|c|c|c|}
\hline Months $/ \alpha_{4}$ & 0.002 & 0.004 & 0.006 & 0.008 \\
\hline 10 & 0.972396 & 0.972314 & 0.972233 & 0.972153 \\
\hline 20 & 0.949026 & 0.948755 & 0.948491 & 0.948232 \\
\hline 30 & 0.929168 & 0.928662 & 0.928171 & 0.927695 \\
\hline 40 & 0.912235 & 0.911480 & 0.910754 & 0.910056 \\
\hline 50 & 0.897745 & 0.896752 & 0.895804 & 0.894899 \\
\hline
\end{tabular}

Table No. 4 shows the effect of failure rate of Subsystem C on the availability of the system, when system goes to failed state from reduced state. The availability of the system decreases by $7.96 \%$ by varying the failure rate from 0.002 to 0.008 in a stepsize of 0.002 .

d) Effect of failure rate of Heat generation system from reduced state to failed state $\left(\alpha_{6}\right)$ on the availability of the system (Table - 5)

\begin{tabular}{|c|c|c|c|c|}
\hline Months $/ \alpha_{6}$ & 0.001 & 0.003 & 0.005 & 0.007 \\
\hline 10 & 0.972396 & 0.972308 & 0.972221 & 0.972135 \\
\hline 20 & 0.949026 & 0.948715 & 0.948411 & 0.948115 \\
\hline 30 & 0.929168 & 0.928548 & 0.927949 & 0.927371 \\
\hline 40 & 0.912235 & 0.911254 & 0.910316 & 0.909418 \\
\hline 50 & 0.897745 & 0.896377 & 0.895079 & 0.893848 \\
\hline
\end{tabular}

A close study of table No. 5 shows the effect of failure rate of Subsystem on the availability of the system, when system goes to failed state from reduced state. The availability of the system decreases by $8.07 \%$ by varying the failure rate from 0.001 to 0.007 in a stepsize of 0.002 .

e) Effect of repair rate of Sugarcane supply system $\left(\beta_{1}\right)$ on the availability of the system. (Table - 6)

\begin{tabular}{|c|c|c|c|c|}
\hline Months/ $\beta_{1}$ & 0.025 & 0.035 & 0.045 & 0.055 \\
\hline 10 & 0.972396 & 0.972798 & 0.973175 & 0.973529 \\
\hline 20 & 0.949026 & 0.950327 & 0.951474 & 0.952488 \\
\hline 30 & 0.929168 & 0.931549 & 0.933531 & 0.935192 \\
\hline 40 & 0.912235 & 0.915695 & 0.918429 & 0.920612 \\
\hline 50 & 0.897745 & 0.902193 & 0.905543 & 0.908112 \\
\hline
\end{tabular}

A close study of table No. 6 shows the effect of repair rate of Subsystem on the availability of the system with variation of repair rate from 0.025 to 0.055 in the step size of 0.01 . The availability of the system increases by $0.11 \%$ and $1.15 \%$ in the span of 50 months.

f) Effect of repair rate of crushing system ( $\beta_{2}$ )on the availability of the system.(Table - 7)

\begin{tabular}{|c|c|c|c|c|}
\hline Months $/ \beta_{2}$ & 0.01 & 0.02 & 0.03 & 0.04 \\
\hline 10 & 0.972396 & 0.973284 & 0.974115 & 0.974895 \\
\hline 20 & 0.949026 & 0.952187 & 0.954967 & 0.957416 \\
\hline 30 & 0.929168 & 0.935515 & 0.940766 & 0.945134 \\
\hline 40 & 0.912235 & 0.922325 & 0.930202 & 0.936413 \\
\hline 50 & 0.897745 & 0.911880 & 0.922319 & 0.930155 \\
\hline
\end{tabular}




\section{International Journal of Science and Research (IJSR) \\ ISSN (Online): 2319-7064 \\ Index Copernicus Value (2013): 6.14 | Impact Factor (2014): 5.611}

A close study of table No. 7 shows the effect of repair rate of Crushing system on the availability of the system with variation of repair rate from 0.01 to 0.04 in the step size of 0.01 . The availability of the system increases by $0.25 \%$ and $3.61 \%$ in the span of 50 months.

\section{Steady State Availability}

The management is always interested in long run availability of the system. Long run availability may be calculated by considering the fact that $\frac{\mathrm{d}}{\mathrm{dt}} \rightarrow 0$ as $\mathrm{t} \rightarrow \infty$. The differential difference equations reduce to:

$$
\begin{aligned}
& \left(\alpha_{1}+\alpha_{2}+\alpha_{3}+\alpha_{5}\right) \mathrm{P}_{0}=\beta_{1} \mathrm{P}_{4}+\beta_{2} \mathrm{P}_{5}+\beta_{3} \mathrm{P}_{1}+\beta_{5} \mathrm{P}_{2} \\
& \left(\alpha_{1}+\alpha_{2}+\alpha_{4}+\alpha_{5}+\beta_{3}\right) \mathrm{P}_{1}=\beta_{1} \mathrm{P}_{6}+\beta_{2} \mathrm{P}_{7}+\beta_{4} \mathrm{P}_{8}+\beta_{5} \mathrm{P}_{3}+\alpha_{3} \mathrm{P}_{0} \\
& \left(\alpha_{1}+\alpha_{2}+\alpha_{3}+\alpha_{6}+\beta_{5}\right) \mathrm{P}_{2}=\beta_{1} \mathrm{P}_{9}+\beta_{2} \mathrm{P}_{10}+\beta_{3} \mathrm{P}_{3}+\beta_{6} \mathrm{P}_{11}+\alpha_{5} \mathrm{P}_{0} \\
& \left(\alpha_{1}+\alpha_{2}+\alpha_{4}+\alpha_{6}+\beta_{3}+\beta_{5}\right) \mathrm{P}_{3}=\beta_{1} \mathrm{P}_{12}+\beta_{2} \mathrm{P}_{13}+\beta_{4} \mathrm{P}_{14}+\beta_{6} \mathrm{P}_{15} \\
& +\alpha_{3} \mathrm{P}_{2}+\alpha_{5} \mathrm{P}_{1} \\
& \beta_{i} \mathrm{P}_{\mathrm{j}}=\alpha_{\mathrm{i}} \mathrm{P}_{\mathrm{k}}
\end{aligned}
$$

Where, (for $\mathrm{i}=1,2: \mathrm{j}=4,5$ when $\mathrm{k}=0)$, (for $\mathrm{i}=1,2,4, \mathrm{j}=$ $6,7,8$ when $\mathrm{k}=1)$, (for $\mathrm{i}=1,2,6: \mathrm{j}=9,10,11$ when $\mathrm{k}=2)$, (for $\mathrm{i}=1,2,4,6: \mathrm{j}=12,13,14,15$ when $\mathrm{k}=3$ )

Solving above equations, we get

$$
\begin{gathered}
\left(\alpha_{3}+\alpha_{5}\right) \mathrm{P}_{0}=\beta_{3} \mathrm{P}_{1}+\beta_{5} \mathrm{P}_{2} \\
\left(\alpha_{5}+\beta_{3}\right) \mathrm{P}_{1}=\beta_{5} \mathrm{P}_{3}+\alpha_{3} \mathrm{P}_{0} \\
\left(\alpha_{3}+\beta_{5}\right) \mathrm{P}_{2}=\beta_{3} \mathrm{P}_{3}+\alpha_{5} \mathrm{P}_{0} \\
\left(\beta_{3}+\beta_{5}\right) \mathrm{P}_{3}=\alpha_{3} \mathrm{P}_{2}+\alpha_{5} \mathrm{P}_{1}
\end{gathered}
$$

After solving these equations recursively we get all the probabilities in terms of $\mathrm{P}_{0}$

$$
\begin{aligned}
& \mathrm{P}_{2}=\frac{\alpha_{5}}{\beta_{5}} \mathrm{P}_{0} \\
& \mathrm{P}_{1}=\frac{\alpha_{3}}{\beta_{3}} \mathrm{P}_{0} \\
& \mathrm{P}_{3}=\frac{\alpha_{3} \alpha_{5}}{\beta_{3} \beta_{5}} \mathrm{P}_{0}
\end{aligned}
$$

Using the normalizing condition we obtain $\mathrm{P}_{0}$

$$
\sum_{\mathrm{i}=0}^{15} \mathrm{P}_{\mathrm{i}}=1
$$

$$
P_{0}=\left[\begin{array}{c}
1+\frac{\alpha_{3}}{\beta_{3}}+\frac{\alpha_{5}}{\beta_{5}}+\frac{\alpha_{3} \alpha_{5}}{\beta_{3} \beta_{5}}+\frac{\alpha_{1}}{\beta_{1}}+\frac{\alpha_{2}}{\beta_{2}} \\
+\frac{\alpha_{1} \alpha_{3}}{\beta_{1} \beta_{3}}+\frac{\alpha_{2} \alpha_{3}}{\beta_{2} \beta_{3}}+\frac{\alpha_{3} \alpha_{4}}{\beta_{3} \beta_{4}}+\frac{\alpha_{1} \alpha_{5}}{\beta_{1} \beta_{5}} \\
+\frac{\alpha_{2} \alpha_{5}}{\beta_{2} \beta_{5}}+\frac{\alpha_{5} \alpha_{6}}{\beta_{5} \beta_{6}}+\frac{\alpha_{1} \alpha_{3} \alpha_{5}}{\beta_{1} \beta_{3} \beta_{5}} \\
+\frac{\alpha_{2} \alpha_{3} \alpha_{5}}{\beta_{2} \beta_{3} \beta_{5}}+\frac{\alpha_{3} \alpha_{4} \alpha_{5}}{\beta_{3} \beta_{4} \beta_{5}}+\frac{\alpha_{3} \alpha_{5} \alpha_{6}}{\beta_{3} \beta_{5} \beta_{6}}
\end{array}\right]^{-1}
$$

The steady state availability of the system is given by

$$
\begin{aligned}
& A_{v}=P_{0}+P_{1}+P_{2}+P_{3} \\
& =\left(1+\frac{\alpha_{3}}{\beta_{3}}+\frac{\alpha_{5}}{\beta_{5}}+\frac{\alpha_{3} \alpha_{5}}{\beta_{3} \beta_{5}}\right) P_{0}
\end{aligned}
$$

\subsection{Steady State Analysis}

For steady state availability assessment the limiting probabilities from equations 1 to 5 have been solved by using recursive method and normalizing condition taking time $\mathrm{t}$ tends to infinity. The performance matrices have been developed with the help of MATLAB 7.8.0 (R2009a) which are shown in the tables no from 8 to11. These matrices show various availability levels for the various combinations of failure and repair rates. The values of failure and repair rates are taken same as mentioned earlier.

a) Effect of failure and repair rate of Sugarcane supply system on the Availability. (Table - 8)

\begin{tabular}{|l|l|l|l|l|}
\hline$\alpha_{1} / \beta_{1}$ & 0.025 & 0.035 & 0.045 & 0.055 \\
\hline 0.001 & 0.7966 & 0.8040 & 0.8081 & 0.8108 \\
\hline 0.002 & 0.7719 & 0.7858 & 0.7938 & 0.7989 \\
\hline 0.003 & 0.7487 & 0.7685 & 0.7800 & 0.7875 \\
\hline 0.004 & 0.7268 & 0.7519 & 0.7666 & 0.7763 \\
\hline
\end{tabular}

Table No. 8 shows that there is an increase in the availability by $1.78 \%$ to $6.81 \%$ with increase in the repair rate from 0.025 to 0.055 of subsystem A. And availability decreases by $8.76 \%$, if failure rate increases from 0.001 to 0.004 .

b) Effect of failure and repair rate of Crushing system on the Availability. (Table - 9)

\begin{tabular}{|l|l|l|l|l|}
\hline$\alpha_{2} / \beta_{2}$ & 0.01 & 0.02 & 0.03 & 0.04 \\
\hline 0.002 & 0.7966 & 0.8659 & 0.8917 & 0.9053 \\
\hline 0.004 & 0.6867 & 0.7966 & 0.8415 & 0.8659 \\
\hline 0.006 & 0.6035 & 0.7376 & 0.7966 & 0.8298 \\
\hline 0.008 & 0.5382 & 0.6867 & 0.7563 & 0.7966 \\
\hline
\end{tabular}

Table No. 9 reveals that there is an increase in the availability by $13.6 \%$ to $48.01 \%$ with increase in the repair rate from 0.01 to 0.04 of subsystem B. And availability decreases by $33.11 \%$ from 0.002 to 0.008 . 


\section{International Journal of Science and Research (IJSR) \\ ISSN (Online): 2319-7064}

Index Copernicus Value (2013): 6.14 | Impact Factor (2014): 5.611

c) Effect of failure and repair rate of Bagasse carrying unit from working state to reduced state on the Availability. (Table - 10)

\begin{tabular}{|c|c|c|c|c|}
\hline$\alpha_{3} / \beta_{3}$ & 0.02 & 0.04 & 0.06 & 0.08 \\
\hline 0.001 & 0.7966 & 0.7995 & 0.8005 & 0.8010 \\
\hline 0.002 & 0.7913 & 0.7966 & 0.7985 & 0.7995 \\
\hline 0.003 & 0.7864 & 0.7939 & 0.7966 & 0.7980 \\
\hline 0.004 & 0.7820 & 0.7913 & 0.7948 & 0.7966 \\
\hline
\end{tabular}

Table No. 10 shows that there is an increase in the availability by $0.5 \%$ to $1.87 \%$ with increase in the repair rate from 0.02 to 0.08 of Subsystem $\mathrm{C}$ from working state to reduced state whereas availability decreases by $1.83 \%$, if failure rate increases from 0.001 to 0.004 .

d) Effect of failure and repair rate of reduced Bagasse carrying unit on the Availability. . (Table - 11)

\begin{tabular}{|c|l|l|l|l|}
\hline$\alpha_{4} / \beta_{4}$ & 0.025 & 0.035 & 0.045 & 0.055 \\
\hline 0.002 & 0.7966 & 0.7973 & 0.7977 & 0.7979 \\
\hline 0.004 & 0.7942 & 0.7956 & 0.7964 & 0.7968 \\
\hline 0.006 & 0.7918 & 0.7939 & 0.7950 & 0.7957 \\
\hline 0.008 & 0.7894 & 0.7921 & 0.7937 & 0.7946 \\
\hline
\end{tabular}

Table No. 11 shows that there is an increase in the availability by $0.16 \%$ to $0.65 \%$ with increase in the repair rate from 0.025 to 0.055 of reduced Subsystem $\mathrm{C}$ whereas availability decreases by $0.90 \%$, if failure rate increases from 0.002 to 0.008 .

e) Effect of failure and repair rate of Heat generation system from working state to reduced state on the Availability. (Table-12)

\begin{tabular}{|c|c|c|c|c|}
\hline$\alpha_{5} / \beta_{5}$ & 0.01 & 0.02 & 0.03 & 0.04 \\
\hline 0.001 & 0.7966 & 0.8001 & 0.8014 & 0.8020 \\
\hline 0.002 & 0.7905 & 0.7966 & 0.7989 & 0.8001 \\
\hline 0.003 & 0.7854 & 0.7934 & 0.7966 & 0.7983 \\
\hline 0.004 & 0.7811 & 0.7905 & 0.7945 & 0.7966 \\
\hline
\end{tabular}

Table No. 12 shows that there is an increase in the availability by $0.67 \%$ to $1.98 \%$ with increase in the repair rate from 0.01 to 0.04 of Subsystem D whereas availability decreases by $1.94 \%$, if failure rate increases from 0.001 to 0.004 .

f) Effect of failure and repair rate of reduced Heat generation system on Availability. (Table - 13)

\begin{tabular}{|l|l|l|l|l|}
\hline$\alpha_{6} / \beta_{6}$ & 0.015 & 0.025 & 0.035 & 0.045 \\
\hline 0.001 & 0.7966 & 0.7982 & 0.7988 & 0.7992 \\
\hline 0.002 & 0.7928 & 0.7958 & 0.7972 & 0.7979 \\
\hline 0.003 & 0.7890 & 0.7935 & 0.7955 & 0.7966 \\
\hline 0.004 & 0.7852 & 0.7912 & 0.7939 & 0.7953 \\
\hline
\end{tabular}

Table No. 13 shows that there is an increase in the availability by $0.32 \%$ to $1.28 \%$ with increase in the repair rate from 0.015 to 0.045 of Subsystem D whereas availability decreases by $1.43 \%$, if failure rate increases from 0.001 to 0.004 .

\section{Analysis of Results}

The objective of this study is to review transient and long run availability in the feeding system of the sugar industry and aims to identify the critical points of the system so that appropriate maintenance strategies can be applied. This can help in increasing the production and quality of the feeding system in the Sugar industry.

Some of the earlier researchers tried to find out reliability of the processing systems by using Laplace transformation method or Lagrange's method which become very difficult in complex systems. The proposed method can be applied to complex system which involve large number of differential equations. Using this method, we can easily study the effects of failure and repair rates of different subsystems on reliability of the complete system. A comparative study of above tables show that the subsystem $\mathrm{B}$ i.e. Crushing system has the maximum impact on the performance of the whole system. The subsystem A i.e. Sugar cane supply system has also a little impact on the availability of the system. The other subsystems (Bagasse carrying unit and Heat generation system) almost have the same effect on the performance of the system respectively. Thus the management and chemical engineers should pay more attention to the subsystem A and B to improve the availability of the system.

\section{References}

[1] Dhillon B S, Singh C, Engineering Reliability - New Techniques and applications, John Willey and Sons, New York; 1981.

[2] Kumar D, Singh I P, and Singh J, Reliability Analysis of the Feeding System in the Paper Industry", Microelectron Reliability, vol. 28, no. 2, 1988, pp. 213 215.

[3] Kumar D, Singh J and Pandey P C, -Axilability Analysis of the Washing System in the Paper Industry", Microelectron Reliability, vol. 29, 1989, pp. 775-778.

[4] Kumar D, Singh J and Pandey P C, -Axilability of the Crystallization System in the Sugar Industry under Common-Cause failure", IEEE Transactions on Reliability, vol. 41, no. 1, pp. 85-91, 1992.

[5] Dayal, B. and Singh, J. (1992), Reliability analysis of a system in a fluctuating environment", Microelectron Reliability, Vol. 32, p.p. 601-3.

[6] Kumar D, Singh J and Pandey P C, - Operational behaviour and Profit function for a Bleaching and Screening system in the Paper industry." Microelectron Reliability, vol. 33, 1993, pp. 1101-1105.

[7] Zhao M, Availability for Repairable components and series systems, IEEE Transactions on Reliability, vol. 43, no. 2, 1994.

[8] Shooman M L, - Reliabity computation for systems with dependent failures", IEEE Annual Symposium on Reliability, 1996.

[9] Michelson Q, Use of Reliability Technology in the Process Industry", Reliability Engineering and System Safety, pp. 179-181, 1998.

[10] Singh J and Mahajan P, Reliability of Utensils Manufacturing Plant - A Case Study", Opsearch, vol. 36, no. 3, pp. 260-269, 1999. 


\section{International Journal of Science and Research (IJSR) \\ ISSN (Online): 2319-7064}

Index Copernicus Value (2013): 6.14 | Impact Factor (2014): 5.611

[11] Gunes, M. and Deveci, I.(2002), -Reliability of service system and an application in student office", International journal of Quality \& Reliability management, Vol. 19, p.p. 206-11.

[12] Habchi, G. (2002), An improved method of reliability assessment for suspended tests", International Journal of Quality \& Reliability Management, Vol. 19, p.p. 454-70.

[13] Castro H F, Cavalco K, -Axilability optimization with Genetic Algorithm", International Journal of Quality and Reliability Management, vol. 20, no. 7, 2003, pp. 847-863.

[14] Tewari P C, D Joshi, M Sreenivasa Rao, Mathematical Modeling and Behavioural Analysis of a Refining System using Genetic Algorithm", National Conference on Competitive Manufacturing Technology and Management for Global Marketing, Chennai, 2005.

[15] Gupta, Lal, Sharma R K, Singh J, Behavioral Study of the Cement manufacturing Plant — A Numerical Approach", Journal of Mathematics and Systems and Sciences, vol. 1, no. 1, pp. 50-69, 2005.

[16] Singh J and Goyal Y, -Axilability and Behavior analysis of bread manufacturing plant", Journal of Mathematics and Systems Sciences, vol. 2, pp. 35-45, 2006.

[17] Kiureghian and Ditlevson, - Axilability, Reliability and Downtime of system with repairable components", Reliability Engineering and System Safety, vol. 92, issue 2, pp. 66-72, 2007.

[18]Enrio Zio and Jussi K. Vaurio Maintenance modeling and applications", Reliability Engineering and System Safety, vol. 94, issue 1, p. 1. 